\title{
Commemorating 50 years since the first heart transplantation in Bratislava - Czechoslovakia
}

\author{
Castillo JG, M.D., Mount Sinai Hospital, New York, USA \\ Slezak J, M.D., DSc., Institute for Heart Research, SAS, Bratislava, SK \\ Reich DL, M.D., Mount Sinai Hospital, New York, USA
}

Text in PDF www.elis.sk.

The first heart transplantation in Czechoslovakia and in Europe and 25th in the world was carried out by professor Siska and his team in Bratislava at the IInd Surgical clinic in summer 1968. The transplantation was preceded by an intensive experimental work of enthusiastic researchers at the Institute of Experimental Surgery of the Slovak Academy of Sciences on dogs. Dogs lived with transplanted heart for several months. In this institute, which was founded also by Prof Siska, scientists were simultaneously working also on extracorporeal circulation, blood substitutes and improved heart storage. The author of the article, Prof Silvay was very active member of the experimental surgery team that time.

After qualifying in medicine at the Medical School of Comenius University, Bratislava, Czechoslovakia, George Silvay pursued a Surgical Internship at the same institution followed by a post-doctoral fellowship at the Second Surgical Department of the University Hospital and Institute of Experimental Surgery, Slovak Academy of Sciences in Bratislava, Czechoslovakia. In the latter role, Doctor Silvay became the key member of a group of emerging physicians led by Professor Ivan Simkovic. At that time, Dr. Silvay left to study in the US, where he remained to work.

George Silvay, MD, PhD serves at The Mount Sinai Hospital as Attending Physician at the Department of Anaesthesiology
(Division of Cardiothoracic Surgery) and Perioperative and Pain Medicine. He is also Full Professor of Anaesthesiology, Icahn School of Medicine at Mount Sinai in New York.

Placing Dr. Silvay's role in context, his career trajectory has been unique. He has contributed to quality of care throughout the world due to his numerous publications, lectures, and numerous prominent international meetings.

Dr. George Silvay is the longest serving anaesthesiology faculty member at the Icahn School of Medicine at Mount Sinai. One of the founding members of the Division of Cardiothoracic Anaesthesia, Dr. Silvay trained countless residents and fellows over fifty years of service at the School of Medicine and The Mount Sinai Hospital. Dr. Silvay's clinical expertise in aortic surgery and brain protection strategies has earned him a coveted international role as one of the foremost experts on this subject. His publications and lectures are renowned.

The innumerable honours Dr. Silvay received include those of Honorary Fellow of The New York Academy of Medicine, Honorary Member of the Czech Society of Surgeons, Honorary Member of the Czech Society of Medicine, and Honorary Member of the Slovak Society of Anaesthesiology and Critical Care. 